Vol. 30, julho 2014, http://dx.doi.org/10.5380/dma.v30i0.34192

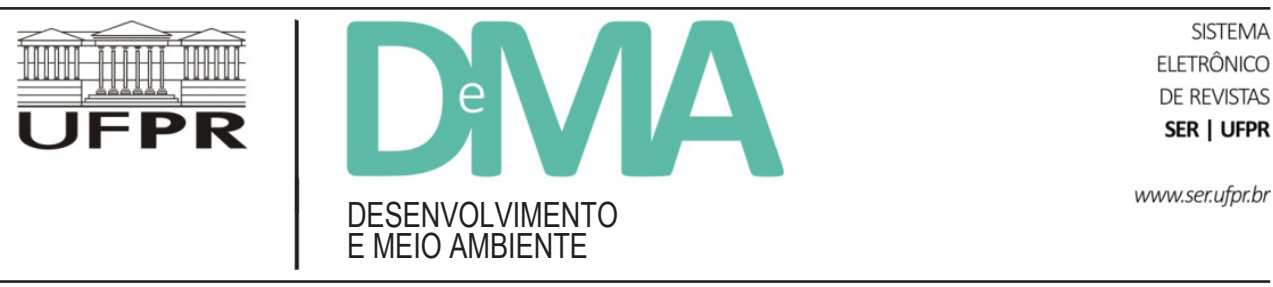

\title{
Incentivos para a viabilização do biogás a partir dos resíduos da pecuária leiteira no Estado de Minas Gerais
}

\section{Incentives for Viability of the Biogas from Waste of Dairy Livestock in the State of Minas Gerais}

\begin{abstract}
Ana Carolina Alves GOMES ${ }^{1}$, Mariana Macedo ROCHA², Aziz da Silva GALVÃO ${ }^{3}$, Pablo Murta Baião $\mathrm{ALBINO}^{4}$

${ }^{1}$ Gestora do Agronegócio (UFV). Mestranda em Desenvolvimento Regional e Agronegócio pela Universidade Estadual do Oeste do Paraná (UNIOESTE). E-mail: anacarolinaufv@gmail.com

${ }^{2}$ Graduanda em Ciências Econômicas com ênfase em Agronegócio (UFV). Bolsista do convênio BiogasFert entre Itaipu Binacional e Embrapa Suínos e Aves. E-mail: marimacedorocha@gmail.com

${ }^{3}$ Doutor em Administração Rural (Universidade de Bonn). Professor do Departamento de Economia Rural da Universidade Federal de Viçosa (UFV).E-mail: aziz@ufv.br

${ }^{4}$ Doutor em Ciências Sociais Aplicadas (Universidad Publica de Navarra). Professor do Departamento de Economia Rural da Universidade Federal de Viçosa (UFV). E-mail: aplconsultores@yahoo.com.br
\end{abstract}

Artigo: Recebido em: 3 de novembro de 2013; Versão final aceita em: 6 de fevereiro de 2014.

RESUMO O avanço tecnológico apresentado pela pecuária brasileira nos últimos anos trouxe muitos benefícios sociais e econômicos. Porém, junto a esse desenvolvimento são originados sérios problemas ambientais em virtude das grandes quantidades de dejetos que, muitas vezes, são direcionados de forma equivocada em lavouras como adubos e fertilizantes orgânicos, ocasionando diversos tipos de poluição na água, no solo e na atmosfera. Assim, este trabalho buscou, por meio da pesquisa bibliográfica, analisar quais são os incentivos e as políticas públicas existentes no Brasil e no Estado de Minas Gerais para o tratamento da problemática em torno dos dejetos de bovinos de leite, por este estado ter o maior plantel leiteiro do país. Concluiu-se que há ações e esforços realizados pelo Governo Federal e pelo Governo Estadual de Minas Gerais, principalmente, as iniciativas estaduais para a melhoria da competitividade da cadeia produtiva de leite. Contudo, identificou-se uma lacuna entre essas iniciativas estaduais para a produção de leite e os programas governamentais para o tratamento dos dejetos gerados na pecuária leiteira.

Palavras-chave: pecuária leiteira; biogás; políticas públicas; regulamentação.

ABSTRACT The technological advances presented by the Brazilian animal husbandry in recent years brought many social and economic benefits. However, along with this development there are serious environmental problems due to the large amounts of waste, which are often mistakenly laid in the fields as organic fertilizers, causing different 
types of pollution in water, air and soil. Thus, this study sought through literature, and analyzed the incentives and the policies for the treatment of problems surrounding dairy cattle manure existing in Brazil as well as in the of State of Minas Gerais, as the largest dairy herd state in the country. It was concluded that there are no actions and efforts from the Federal Government and the State Government of Minas Gerais, mainly from state initiatives, to improve the competitiveness of the supply chain of milk. However, it was identified a gap between these state initiatives for the production of milk and the government programs for the treatment of dairy cattle manure.

Keywords: dairy farming; biogas; public policy; regulation.

\section{Introdução}

O desempenho da agropecuária destaca-se no cenário nacional, contribuindo na geração de divisas pela exportação de carnes e derivados, empregos e renda, que, segundo Oliveira (1993), provoca efeitos multiplicadores de renda e emprego em todos os setores da economia, intensificando a demanda de insumos agropecuários e a expansão e a modernização dos setores de comercialização e agroindústrias.

Nesse contexto, o Estado de Minas Gerais ganha destaque por possuir o maior rebanho leiteiro do país, sendo o primeiro no ranking nacional, produzindo $27,6 \%$ do volume de leite (Instituto Brasileiro de Geografia e Estatística - IBGE, 2013). Porém, o volume de dejetos também é significativo, gerando um grande problema ambiental devido à emissão de gases causadores do efeito estufa e à poluição das águas. Uma forma de minimizar esse passivo ambiental é feita por meio da produção de biogás. Mas, para que esta atividade seja viável, é necessário que incentivos governamentais sejam viabilizados e a regulamentação do setor se torne realidade.

É sabido que a viabilização do biogás (e da agroenergia como um todo) tem relação direta com a adoção de tecnologias, pesquisas e desenvolvimento. Para tanto, acredita-se que a promoção de incentivos aos produtores, em conjunto com o fortalecimento de políticas públicas e com a regulamentação do setor, possibilitarão a concretização destas ações, tornando o biogás uma alternativa de negócio.

Nos países desenvolvidos, a geração de eletricidade por meio de biogás é uma realidade, porém no Brasil ainda necessitamos de estudos e análises dos pontos de vista técnico e econômico que comprovem a efetividade desta tecnologia (Oliveira \& Ramalho, 2006).
Diante da importância da atividade leiteira para o desenvolvimento socioeconômico e, por consequência, da possibilidade de geração de energia renovável e seu papel enquanto alternativa ao cumprimento da legislação ambiental, fica evidente a necessidade de um estudo que busque conhecer o que vem sendo feito para a viabilização do tratamento dos resíduos da pecuária leiteira.

Com isso, este trabalho tem como objetivo descrever os incentivos que vêm sendo construídos para a viabilização do biogás enquanto alternativa para minimizar os problemas ambientais, principalmente aqueles relacionados à água, enfrentados pela pecuária leiteira no Estado de Minas Gerais.

O texto está estruturado em cinco seções além desta introdução, em que na segunda seção é descrita uma breve apresentação da pecuária leiteira e os problemas que esta atividade enfrenta do ponto de vista ambiental. A metodologia utilizada para elaboração deste estudo é abordada na terceira seção, seguida da quarta seção, em que o biogás é abordado como possível alternativa para minimização das externalidades negativas ocasionadas pela atividade animal, enquanto na seção cinco é exposto o levantamento dos incentivos e políticas públicas voltadas para a produção de biogás, e, por fim, são feitas algumas considerações finais acerca de todo o trabalho.

\section{Pecuária leiteira em Minas Gerais: panorama e problemática}

A produção pecuária nacional, no ano de 2011, foi de aproximadamente 212,8 milhões de cabeças bovinas, 39,3 milhões de suínos e 1,3 bilhão de aves. O Estado de Minas Gerais obteve destaque nessa produção, contribuindo com $9,2 \%$ da produção de aves, $12,8 \%$ dos 
suínos, 11,2\% de bovinos (Secretaria de Agricultura, Pecuária e Abastecimento de Minas Gerais - SEAPA-MG, 2013).

Além das carnes, outro produto importante para a agropecuária é o leite, sendo que cerca de 22,8 milhões de vacas foram ordenhadas em 2012 no território nacional, produzindo 32,3 milhões de litros de leite. Minas Gerais também superou a produção de leite do ano anterior, com ganhos de $0,9 \%$ na produtividade, indo de 1.555 litros/ vaca/ano em 2011 para 1.570 litros/vaca/ano em 2012, produzindo neste último ano cerca de 8,9 milhões de litros de leite (SEAPA-MG, 2013).

De acordo com Oliveira (2004), o avanço tecnológico apresentado pela pecuária brasileira nos últimos anos trouxe benefícios sociais e econômicos já citados, porém, junto a esse desenvolvimento são originados sérios problemas ambientais, principalmente nos grandes centros produtores do país.
O abundante número de animais gera grandes quantidades de dejetos que, muitas vezes, são direcionados para as lavouras como adubos e fertilizantes orgânicos, porém, se utilizados de forma inadequada ou excessiva, possibilitam diversos tipos de poluições, como pode ser observado na Tabela 1.

Segundo Sganzerla (1983), em média, os bovinos produzem cerca de $10 \mathrm{~kg}$ de dejetos por dia, possibilitando uma produção média de $270 \mathrm{~m}^{3}$ de biogás por tonelada. Dessa forma, estima-se uma produção de dejetos do rebanho leiteiro em Minas Gerais na ordem de $89 \mathrm{mil}$ toneladas de dejetos por dia, ou 32,5 milhões por ano.

Ainda de acordo com o autor, o biogás é produto final da fermentação anaeróbica de dejetos animais e demais resíduos orgânicos, composto em média por $65 \%$ de metano e $35 \%$ de gás carbônico; além disso, é considerado como fonte de produção de calor (energia

TABELA 1 - Aspectos e impactos ambientais causados por tipo de poluição gerada pela exposição dos dejetos animais no ambiente.

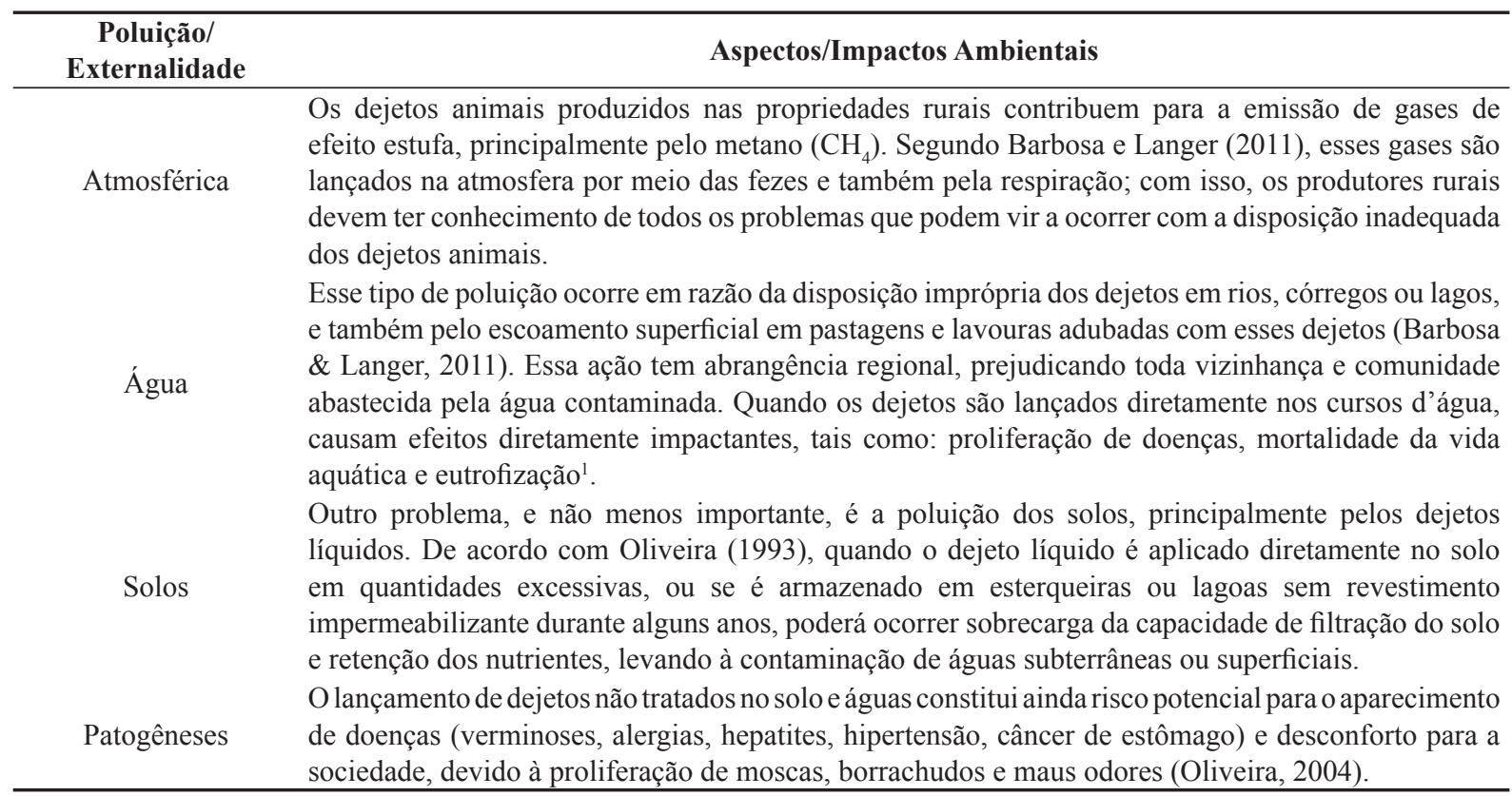

FONTE: Elaborado pelos autores de acordo com Barbosa e Langer (2011); Oliveira (1993); Oliveira (2004).

${ }^{1}$ Processo de degradação que sofrem os lagos e outros corpos d'água quando excessivamente enriquecidos de nutrientes, principalmente nitrogênio e fósforo, que limitam a atividade biológica (Beck, 2007). 
térmica), acionamento de motores de combustão interna (energia veicular) e iluminação (energia elétrica).

A produção de biogás por meio dos dejetos da bovinocultura de corte, apesar do seu elevado potencial, pouco pode ser utilizada, visto que a maior parte das unidades é de caráter extensivo, com pouco ou nenhum tempo de confinamento. Já a bovinocultura de leite possui maior possibilidade de aproveitamento do seu potencial, uma vez que a maior parte do plantel, mesmo que por pouco tempo, fica confinado (Oliveira et al., 2010).

Dessa forma, torna-se importante o incentivo à utilização de alternativas para o tratamento adequado dos dejetos dos animais para que esses obtenham menor impacto para o meio ambiente.

\section{Metodologia}

A metodologia utilizada nesse artigo baseou-se na pesquisa bibliográfica, buscando descrever quais incentivos e políticas públicas existem hoje no Brasil, especificamente em Minas Gerais, para o tratamento da problemática em torno dos dejetos da pecuária leiteira existente nas propriedades rurais do Estado de Minas Gerais, por ser o maior produtor de leite do país.

Para identificar a existência de leis e incentivos relacionados ao tratamento dos dejetos da pecuária leiteira no Estado de Minas Gerais e a geração de biogás, foram consultadas fontes de dados secundárias que nortearam a discussão sobre os temas abordados neste trabalho.

Para tanto, buscou-se sites oficiais do Governo Brasileiro e do Governo do Estado de Minas Gerais para verificar os incentivos que acontecem por meio das políticas públicas, tais como: Plano Nacional de Agroenergia, Programa de Agricultura de Baixo Carbono (ABC), Programa Nacional para a Agricultura Familiar (PRONAF-Sustentável), Programa de Incentivo às Fontes Alternativas de Energia (PROINFA), Plano Nacional do Meio Ambiente/CONAMA, Plano Nacional dos Resíduos Sólidos, Plano Estadual dos Resíduos Sólidos, Novo Código Florestal, Política Florestal e de Proteção à Biodiversidade no Estado, Programa para Redução da Emissão de Gases de Efeito Estufa na Agricultura e o Plano Setorial de Mitigação e de Adaptação às Mudanças Climáticas para a Consolidação de uma Economia de Baixa Emissão de Carbono na Agricultura.
Com relação aos incentivos para a produção de leite em Minas Gerais, buscou-se informações por meio de programas estaduais consolidados nesta cadeia produtiva, como o "Programa Minas Leite" e "Balde Cheio", além de dados produzidos pela Secretaria de Estado de Agricultura, Pecuária e Abastecimento de Minas Gerais (SEAPA-MG), pela Empresa de Assistência Técnica e Extensão Rural do Estado de Minas Gerais (EMATER-MG), pela Federação da Agricultura e Pecuária do Estado de Minas Gerais (FAEMG) e pelo Programa de Desenvolvimento da Pecuária Leiteira da Região de Viçosa (PDPL-RV).

\section{Produção de biogás: possíveis alternativas para o tratamento dos dejetos da atividade leiteira}

Atualmente, há diversos estudos e tecnologias que podem auxiliar na minimização dos problemas ambientais causados pela produção animal, além de agregar valor ao dejeto. Essa tecnologia é o biodigestor, um sistema que pode gerar biogás a partir de dejetos animais e que proporciona resultados diretos (geração de energias e biofertilizantes) e indiretos (demanda por serviços de planejamento, implantação, operação e manutenção dos processos que produzem o biogás e das energias que com ele podem ser geradas).

As tecnologias aplicadas ao tratamento adequado dos dejetos animais para a produção de biogás, sua utilização e benefícios aqui mencionados não terão aprofundamento técnico em virtude de este não ser o objetivo do presente trabalho.

De acordo com Oliveira (1993), as principais técnicas de tratamento dos dejetos animais podem ser realizadas por meio de tratamento físico (separação de fases ou desidratação) ou por meio biológico, por meio do tratamento aeróbio (compostagem, lagoas de estabilização facultativas ou aeradas, diques de oxidação) ou anaeróbio (digestores anaeróbios ou biodigestores, sem a presença de oxigênio).

Para Kunz e Oliveira (2008), “o biodigestor é um reator biológico que degrada os dejetos animais em condições anaeróbias (ausência de oxigênio), produzindo um efluente líquido (biofertilizante) e gerando o biogás". 
Existem vários modelos de biodigestores, mas, em geral, todos são compostos, basicamente, de duas partes: um recipiente (tanque) para abrigar e permitir a digestão da biomassa e o gasômetro (campânula) para armazenar o biogás (Gaspar, 2003).

Em propriedades rurais, os modelos de biodigestores são considerados mais simples, construídos em alvenaria (modelos indiano e chinês) ou de lona (modelo canadense) e apresentam baixo custo de implantação, devido à baixa tecnologia associada e à operacionalização facilitada.

Sobre as tecnologias recentes para biogás na bovinocultura, há alguns equipamentos utilizados especificamente para essa atividade, tais como: separador de sólidos, também conhecido como extrusor ou "ecofiltro", que separa o resíduo líquido do sólido e demais partículas sólidas presentes no dejeto, tais como fibras. Tal equipamento possibilita o aproveitamento dos resíduos sólidos separados, sendo utilizados na adubação de lavoura, visto a riqueza de nutrientes presentes no material. Além disso, há tanques de mistura (processo executado antes da separação de sólidos), agitador, entre outros. Cada tecnologia é aplicada de acordo com as características do sistema de produção animal, das condições de manejo e das instalações da propriedade.

Isto posto, percebe-se que a implantação dos biodigestores pode ocasionar algumas vantagens e desvantagens, a saber:

- VANTAGENS: Fornecimento de energia (térmica, elétrica e veicular) no meio rural com o uso do biogás; Redução dos gastos do produtor com compra de energia e insumos; Promoção da interação entre as atividades produtivas na propriedade por meio do manejo dos fluxos de energia e nutrientes; Exigência de menor tempo de retenção hidráulica e de área em comparação com outros sistemas de manejo e tratamento (ex.: lagoas e esterqueiras); Substituição do GLP em sistemas de aquecimento do ambiente interno e utilização em fogões adaptados (ex.: em aviários, produção de leitão); Valorização dos dejetos como adubo orgânico (biofertilizante); Substituir o consumo de energias não renováveis por energia renovável; Conscientizar o produtor para a importância do tratamento dos dejetos por sua viabilidade econômica e ambiental; Redução do poder poluente e do nível de patógenos; Reduz significativamente a quantidade emitida de dióxido de carbono $\left(\mathrm{CO}_{2}\right)$ e de metano $\left(\mathrm{CH}_{4}\right)$, gases causadores do efeito estufa; É um processo natural para tratamento de rejeitos orgânicos; Diminui o volume de resíduo a ser descartado, reduzindo o impacto ambiental da atividade suinícola; Redução de odores; e Requer menos espaço que aterros sanitários corrosivos (Oliveira, 2004a; Salomom \& Tiago Filho, 2007).

- DESVANTAGENS: A produção de biogás é dependente das condições climáticas da região, pois a temperatura da biomassa determina a velocidade das reações anaeróbias que ocorrem na câmara de fermentação; O sistema é sensível a descargas de detergentes e desinfetantes; $\mathrm{O}$ modelo canadense tem como desvantagens a pressão variável do gás produzido, necessitando de compressor para o transporte e uso em sistema de aquecimento com queimadores que trabalham com pressão constante; Formação de gás sulfídrico, gás tóxico com cheiro desagradável; e Custo extra de manutenção devido à escolha do material utilizado na construção do biodigestor, pois há formação de gases corrosivos (Oliveira, 2004a; Salomom \& Tiago Filho, 2007).

Frente a isso, destaca-se a importância do biogás na substituição de fontes energéticas tradicionais.

Pode-se observar, na Tabela 2, o potencial de geração de biogás a partir de diferentes resíduos orgânicos de animais. Sendo assim, um bovino que pesa em média $500 \mathrm{~kg}$ produz de 10 a $15 \mathrm{~kg}$ de esterco por dia, sendo que $1 \mathrm{~kg}$ de esterco desse animal equivale a $0,038 \mathrm{~m}^{3}$ de biogás e $1 \mathrm{~kg}$ de sólidos voláteis tem de 0,094 a 0,31 $\mathrm{m}^{3}$ de biogás. Logo, esse animal produz um total diário de 0,36 $\mathrm{m}^{3}$ de biogás (Oliveira, 2001).

$\mathrm{Na}$ Tabela 3 encontra-se a equivalência obtida do $\mathrm{m}^{3}$ do biogás se comparado a outras fontes de energia.

Ainda, o biogás produzido pode ser utilizado com outras funcionalidades, como apresentado na Tabela 4:

Desta forma, segundo informações de ICLEI (2009), ao considerarmos o uso do biogás, resumidamente constata-se ser possível obter uma significativa redução de custos para suprir as demandas de: i) Energia 
TABELA 2 - Potencial de geração de biogás a partir de diferentes resíduos orgânicos de animais.

\begin{tabular}{ccccc}
\hline $\begin{array}{c}\text { Animal } \\
\text { (peso vivo) }\end{array}$ & $\begin{array}{c}\mathbf{K g} \\
\text { Esterco/animal/dia }\end{array}$ & $\begin{array}{c}\mathbf{m}^{\mathbf{3}} \\
\text { biogás/kg esterco }\end{array}$ & $\begin{array}{c}\mathbf{m}^{\mathbf{3}} \\
\text { biogás } / \mathbf{k g ~ S V}\end{array}$ & $\begin{array}{c}\mathbf{m}^{\mathbf{3}} \\
\text { biogás/animal/dia }\end{array}$ \\
\hline $\begin{array}{c}\text { Bovino } \\
(500 \mathrm{~kg})\end{array}$ & $10-15$ & 0,038 & $0,094-0,31$ & 0,36 \\
$\begin{array}{c}\text { Súnos } \\
(90 \mathrm{~kg})\end{array}$ & $2,3-2,8$ & 0,079 & $0,37-0,50$ & 0,24 \\
$\quad \begin{array}{l}\text { Aves } \\
(2,5 \mathrm{~kg})\end{array}$ & $0,12-0,18$ & 0,050 & $0,31-0,62$ & 0,014 \\
\hline
\end{tabular}

FONTE: Machado (2011), p.22 apud Oliveira (2001)

*SV = sólidos voláteis

TABELA 3 - Comparação entre o biogás e outros combustíveis.

\begin{tabular}{cc}
\hline Combustíveis & $\mathbf{1 ~ m}^{\mathbf{3}}$ de biogás equivale a \\
\hline Gasolina & 0,613 litro \\
Querosene & 0,579 litro \\
Óleo diesel & 0,553 litro \\
Gás de cozinha (GLP) & 0,454 litro \\
Lenha & $1,536 \mathrm{~kg}$ \\
Álcool hidratado & 0,790 litro \\
Eletricidade & $1,428 \mathrm{~kW}$ \\
\hline
\end{tabular}

FONTE: Barrera (1993), p. 10 apud Gaspar (2003).

TABELA 4 - Consumo de biogás em diferentes atividades específicas.

\begin{tabular}{|c|c|c|}
\hline Atividade & Especificação & Consumo/Biogás \\
\hline Cozimento & Pessoa/dia & 0,34 a $0,42 \mathrm{~m}^{3} / \mathrm{h}$ \\
\hline \multirow{2}{*}{ Iluminação } & Lâmpada/100 W & $0,13 \mathrm{~m}^{3} / \mathrm{h}$ \\
\hline & Camisa/40 W (Lampião) & 0,45 a $0,51 \mathrm{~m}^{3} / \mathrm{h}$ \\
\hline Motor a Gasolina ou Diesel & Biogás/HP (25\% Eficiência) & 0,45 a $0,51 \mathrm{~m}^{3} / \mathrm{h}$ \\
\hline Incubadora & Por $\mathrm{m}^{3}$ de capacidade & 0,46 a $0,71 \mathrm{~m}^{3} / \mathrm{h}$ \\
\hline Água (Ebulição) & Litro & $0,11 \mathrm{~m}^{3} / \mathrm{h}$ \\
\hline Gasolina & Litro & $1,33 \mathrm{~m}^{3}$ \\
\hline Diesel & Litro & 1,6 a $2,07 \mathrm{~m}^{3}$ \\
\hline Óleo Fuel (caldeira) & Litro & 1,4 a $1,8 \mathrm{~m}^{3}$ \\
\hline Eletricidade & $\mathrm{kWh}$ & $0,62 \mathrm{~m}^{3} / \mathrm{h}$ \\
\hline Campânula aquecimento & 1.400 kW (suínos/aves) & $0,15 \mathrm{~m}^{3} / \mathrm{h}-0,17 \mathrm{~m}^{3} / \mathrm{h}$ \\
\hline
\end{tabular}

FONTE: Biomass Energy Institute (1978); La Farge (1995) apud Oliveira, 2004

elétrica: para uso próprio, em indústrias próximas ou consumidores distantes, neste último caso, por meio da venda e distribuição dessa energia via rede já existente; ii) Energia térmica (calor): útil em processos como secagem de grãos, aquecimento de granjas e água, esterilização de equipamentos e usos industriais diversos; iii) Com- bustíveis veiculares: para abastecimento de caminhões e máquinas agrícolas da propriedade, veículos públicos e particulares adaptados; e iv) Iluminação: privada, na utilização de lâmpadas adaptadas, e pública, por meio do uso de postes abastecidos diretamente com o biogás. 
Percebe-se que o biogás tem, hoje, um papel fundamental, em parte por sua contribuição para a questão ambiental, na garantia do suprimento de energia e na redução das tarifas de energia, podendo tornar-se uma das três grandes fontes de combustível do Brasil, além de renovar a matriz energética do país (FRAGMAQ, 2012).

Sua importância também pode ser identificada quando segmentado por escala de produção. Em pequena escala, os biodigestores podem gerar energia para as propriedades rurais, além da venda do excedente do gás para consumidores. Outro aspecto que indica a importância do biogás são as chamadas públicas para geração distribuída e a nova regulamentação para este tipo de geração (Resolução n. ${ }^{\circ} 482$ da Agência Nacional de Energia Elétrica - ANEEL). Já em grandes escalas, pode-se citar a diminuição da pressão sobre os aterros sanitários, os leilões de energia nova e de fontes alternativas (Decreto n. ${ }^{\circ}$ 5.163/04) e os leilões de reserva por fonte específica (Lei n. $\left.{ }^{\circ} 10.848 / 04\right)$.

Por fim, o processo de conversão de biomassa em energia vem sendo uma alternativa viável para os produtores reduzirem os custos energéticos nas propriedades, reduzindo os impactos negativos gerados ao meio ambiente e adequação às legislações vigentes. Logo, percebe-se a necessidade de se conhecer as ações e incentivos para a promoção dessa alternativa no meio rural.

\section{Políticas públicas nacionais para produção de biogás}

No Brasil, há várias fontes de incentivos para a promoção da energia da biomassa residual, tais como: o Plano Nacional de Agroenergia, o Programa de Agricultura de Baixo Carbono, o Programa Nacional para a Agricultura Familiar (PRONAF), o Programa de Incentivo às Fontes Alternativas de Energia (PROINFA), entre outros.

"O Plano Nacional de Agroenergia visa organizar e desenvolver proposta de pesquisa, desenvolvimento, inovação e transferência de tecnologia para garantir sustentabilidade e competitividade às cadeias de agroenergia" (Ministério da Agricultura, Pecuária e Abastecimento - MAPA, 2006, p. 7). Dentre as prioridades do programa ressalta-se o desenvolvimento de estudos e modelos de biodigestores; a avaliação do uso de biofertilizante como adubo orgânico; o desenvolvimento de equipamentos para o transporte do biofertilizante e para o aproveitamento de biogás como fonte de calor, energia elétrica e combustível, além de processos de purificação do biogás e compressão e armazenamento deste.

Dentro das linhas de crédito do PRONAF há uma específica para questões de sustentabilidade ambiental, o PRONAF Eco. Essa linha atua na área de fornecimento de crédito para "[...] o financiamento de investimentos em técnicas que minimizem o impacto da atividade rural ao meio ambiente, bem como permitam ao agricultor melhor convívio com o bioma em que sua propriedade está inserida" (Ministério do Desenvolvimento Agrário - MDA, 2013, p. 1).

O Brasil também conta com o PROINFA, que teve o "[...] objetivo de aumentar a participação da energia elétrica produzida por empreendimentos concebidos com base em fontes eólica, biomassa e pequenas centrais hidrelétricas $(\mathrm{PCH})$ no Sistema Elétrico Interligado Nacional (SIN) [...]" (Ministério de Minas e Energia - MME, 2013, p. 1). Com isso, de acordo com Souza et al. (2004), abriu-se oportunidade para implantação de tecnologias que utilizam biomassa para produção de biogás para abastecimento elétrico, promovendo, assim, a participação dessa fonte renovável alternativa de energia na matriz energética nacional. Segundo a ELETROBRAS, Centrais Elétricas Brasileiras, que é a responsável pela comercialização da energia gerada pelos empreendimentos contratados no âmbito do PROINFA por 20 anos, foi implantado um total de 119 empreendimentos, sendo 41 eólicas, 59 PCHs e 19 térmicas a biomassa até 31 de dezembro de 2011. O programa continuou vigente até o ano de 2013, cujas metas foram contratar energia de 130 empreendimentos, um potencial instalado de 2.874,30 (MW) e 11.032.511,00 (MWh) de energia, conforme pode ser visualizado na Tabela 5, em que é apresentado o total de potência instalada e energia elétrica geradas por cada tipo de fonte, respectivamente.

A partir da Politica Nacional do Meio Ambiente, foi constituído o Sistema Nacional do Meio Ambiente, criado o CONAMA - Conselho Nacional do Meio Ambiente - e instituído o Cadastro Técnico Federal de Atividades e Instrumentos de Defesa Ambiental, sendo a Resolução n. ${ }^{\circ} 357$ de 17/03/05, do CONAMA, 
TABELA 5 - Energia contratada pelo PROINFA, em 2013, por fonte.

\begin{tabular}{cccc}
\hline Fonte & $\mathbf{N}^{\mathbf{0}}$ de empreendimentos & Potência instalada (MW) & $\begin{array}{c}\text { Energia } \\
(\mathbf{M W h})\end{array}$ \\
\hline Biomassa & 19 & 533,34 & $1.193 .859,00$ \\
Eólica & 51 & $1.181,72$ & $3.281 .788,00$ \\
PCH & 60 & $1.159,24$ & $6.556 .864,00$ \\
Total & $\mathbf{1 3 0}$ & $\mathbf{2 . 8 7 4 , 3 0}$ & $\mathbf{1 1 . 0 3 2 . 5 1 1 , 0 0}$ \\
\hline
\end{tabular}

FONTE: Plano Anual do PROINFA (PAP, 2013).

importante ser citada nesse estudo, pois define que a legislação ambiental estabelece normas e padrões para a qualidade das águas e o lançamento de efluentes nos corpos de água. Ainda há incentivos para o tratamento dos efluentes, como é colocado na Resolução n. ${ }^{\circ} 430$ de 2011, do Conselho Nacional do Meio Ambiente (CONAMA), que aponta as condições e padrões de lançamento de efluentes, complementando e alterando a Resolução n. ${ }^{\circ} 357 / 2005$, que em seu parágrafo único dispõe:

O órgão ambiental competente poderá, a qualquer momento, mediante fundamentação técnica: (i) Acrescentar outras condições e padrões para o lançamento de efluentes, ou torná-los mais restritivos, tendo em vista as condições do corpo receptor; ou, (ii) Exigir tecnologia ambientalmente adequada e economicamente viável para o tratamento dos efluentes, compatível com as condições do respectivo corpo receptor (BRASIL, 2005, p. 1).

O CONAMA também é responsável pela Lei n. ${ }^{\circ}$ 12.305/10, que instituiu o Plano Nacional de Resíduos Sólidos - PNRS -, o qual visa, principalmente, à mitigação de problemas ambientais, sociais e econômicos referentes aos resíduos. Para isso, a reciclagem, a reutilização e o descarte correto de rejeitos são ações que ajudam o país a alcançar a meta do Plano Nacional sobre Mudança do Clima, que é a de que o índice de reciclagem de resíduos atinja $20 \%$ até 2015. Algumas iniciativas, como a Coleta Seletiva e a Logística Reversa, vêm sendo desenvolvidas em todo o país com grande êxito, além da batalha para eliminação dos lixões (Ministério do Meio Ambiente - MMA, 2013).

$\mathrm{Na}$ esfera nacional, o Novo Código Florestal traz como principal objetivo o desenvolvimento sustentável, em que a Lei n. ${ }^{\circ} 12.651$, de 25 de maio de 2012, estabele- ce normas gerais sobre a proteção da vegetação, as áreas de Preservação Permanente e as áreas de Reserva Legal; a exploração florestal, o suprimento de matéria-prima florestal, o controle da origem dos produtos florestais e o controle e prevenção dos incêndios florestais, e prevê instrumentos econômicos e financeiros para o alcance de seus objetivos (MMA, 2012).

Como opção de financiamento a projetos de baixa emissão de carbono, o Banco Nacional do Desenvolvimento - BNDES - possui o Programa ABC - Programa para Redução da Emissão de Gases de Efeito Estufa na Agricultura, que tem por objetivos promover a redução das emissões de gases de efeito estufa oriundas das atividades agropecuárias e do desmatamento; aumentar a produção agropecuária em bases sustentáveis; adequar as propriedades rurais à legislação ambiental; ampliar a área de florestas cultivadas; e estimular a recuperação de áreas degradadas. Dentro dessa ótica, há o programa para "Tratamento de Dejetos Animais", em que se propõe disponibilizar, por intermédio de crédito aos produtores de suínos, aves e bovinos de leite e corte, cooperativas e associações, os investimentos necessários para adequação da adoção de tecnologias de tratamento de dejetos e efluentes dos animais. Para estes itens, o limite pode ser de até $100 \%$ do valor do financiamento, com prazo total de até 10 anos, incluindo o período de carência de até 5 anos (Banco Nacional do Desenvolvimento Econômico e Social - BNDES, 2013).

Tais políticas nacionais são o ponto de partida para que os Estados hajam de forma a adequarem essas políticas nacionais à realidade do Estado. Por isso, o próximo tópico buscou fazer esse levantamento de políticas públicas existentes no Estado de Minas Gerais para a produção de biogás. 


\subsection{Políticas públicas para a produção de biogás no Estado de Minas Gerais}

Como o foco deste trabalho é o Estado de Minas Gerais, verificou-se que o Estado possui uma Política Estadual de Resíduos Sólidos, na qual, em uma parte das disposições finais e transitórias, é citada a possibilidade de criar linhas de financiamento para iniciativas de aproveitamento energético ou de resíduos sólidos orgânicos de origem urbana e rural, proveniente da pecuária intensiva (MMA, Lei n ${ }^{\circ} 18.031$, de 12 de janeiro de 2009).

Em relação à Legislação Ambiental do Estado de Minas Gerais, classifica as águas e seu uso, sendo então, criados os padrões de lançamentos de efluentes (SEAPA-MG, 2013).

No dia 17 de outubro de 2013, foi publicada pelo Governo do Estado a lei denominada "Política Florestal e de Proteção à Biodiversidade no Estado", que, no parágrafo único do Art. 1. ${ }^{\circ}$, diz:

As políticas florestal e de proteção à biodiversidade no Estado compreendem as ações empreendidas pelo poder público e pela coletividade para o uso sustentável dos recursos naturais e para a conservação do meio ambiente ecologicamente equilibrado, essencial à sadia qualidade de vida, nos termos dos Arts. 214, 216 e 217 da Constituição do Estado (SEAPA-MG, Lei no 20.922 de 2013, p. 1).

De acordo com o exposto, o planejamento é que os incentivos fiscais e espaciais sejam concedidos para pessoa física ou jurídica com o intuito de preservar e conservar a vegetação nativa e cursos d'água, recuperar as áreas degradadas, realizar a prática de técnicas de agricultura de baixa emissão de carbono e contribuir para a implantação e manutenção de Unidades de Conservação estaduais. Os parágrafos $1 .^{\circ}$ e $2 .^{\circ}$ do Art. 72 da Lei 20.922, apelidada de "Lei Florestal Mineira", ressaltam a importância do aproveitamento socioeconômico e ambiental dos produtos, subprodutos e dos resíduos florestais. Para isso, será necessário estabelecer quais serão os critérios para que tal aproveitamento ocorra.

Os artigos citados acima, da Constituição Estadual de Minas Gerais, falam de um meio ambiente que deve ser conservado no presente para que no futuro o povo mineiro possa usufruir dos mesmos recursos ambientais e naturais que existem no mesmo hoje. Além disso, cita a necessidade de criar mecanismos de fomento, por exemplo, para conservação e recuperação da qualidade da água e do ar. O que implica que os dejetos de bovinos não podem ser jogados nos rios. $\mathrm{E}$, por fim, o último artigo citado diz respeito às atividades que utilizam de produtos florestais como insumo (Assembleia Legislativa do Estado de Minas Gerais - ALMG, 2013).

Por meio dos programas e das leis nacionais e estaduais apresentadas, é importante observar que estas não possuem uma interconexão que permita colocar a produção de biogás a partir de dejetos de animais como uma possível ação importantíssima dos pontos de vista ambiental e econômico. Além dos programas já analisados, torna-se necessário verificar ainda os programas que têm como foco a pecuária leiteira, a fim de conhecer seus objetivos e como tratam a gestão sustentável das propriedades assistidas, além das ações consolidadas desses programas que levam ao pequeno, médio e grande produtores de leite benefícios sociais, econômicos e ambientais.

Portanto, os programas visam incentivar a cadeia produtiva do leite por meio de assistência técnica ao produtor rural, alinhada à disseminação de conhecimento e novas tecnologias, a saber: i) Programa de Qualificação Técnica e Gerencial dos Sistemas de Produção de Pecuária Bovina do Estado de Minas Gerais - Minas Leite; ii) Balde Cheio; e iii) Programa de Desenvolvimento da Pecuária Leiteira da Região de Viçosa - PDPL-RV.

O "Programa de Qualificação Técnica e Gerencial dos Sistemas de Produção de Pecuária Bovina do Estado de Minas Gerais", popularmente conhecido como Programa "Minas Leite", iniciou suas atividades em dezembro de 2005, por intermédio de decreto do Governo do Estado, sendo que a coordenação é de responsabilidade da Secretaria de Estado de Agricultura, Pecuária e Abastecimento - SEAPA/MG, com a responsabilidade de execução da Empresa de Assistência Técnica e Extensão Rural do Estado de Minas Gerais - EMATER-MG, em parceria com a Empresa de Pesquisa Agropecuária de Minas Gerais - EPAMIG.

O objetivo do "Minas Leite" é promover ações gerenciais e técnicas que visem à produção sustentável 
da pecuária bovina no Estado. Tais ações são pautadas na utilização de tecnologia, também com o intuito de reduzir os custos da produção e aumentar a renda familiar do produtor rural, para que as atividades, tanto de campo quanto de pesquisa, por exemplo, em laboratórios, possam gerar resultados positivos.

Outro Programa específico para a cadeia produtiva do leite do Estado de Minas Gerais que vem se destacando em todo o país é o "Balde Cheio", que foi criado na Empresa Brasileira de Pesquisa Agropecuária - EMBRAPA Pecuária Sudeste - e que define o Programa da seguinte forma:

O Programa Balde Cheio é uma metodologia inédita de transferência de tecnologia que contribui para o desenvolvimento da pecuária leiteira em propriedades familiares. Seu objetivo é capacitar profissionais de extensão rural e produtores, promover a troca de informações sobre as tecnologias aplicadas regionalmente e monitorar os impactos ambientais, econômicos e sociais, nos sistemas de produção que adotam as tecnologias propostas (EMBRAPA Pecuária Sudeste, 2013, p. 1).

Desta forma, o Sistema da Federação da Agricultura e Pecuária do Estado de Minas Gerais (FAEMG) trouxe o Programa "Balde Cheio" para o Estado, o qual já conta com milhares de propriedades rurais assistidas nas várias mesorregiões de Minas Gerais. Para que o adequado manejo dos dejetos da pecuária de leite seja feito nestes e em outros vários programas, se observa a necessidade de leis federais e estaduais que regulamentem e tragam mais informações sobre a produção de biogás a partir dos dejetos de bovinos (FAEMG, 2013).

Por fim, o Programa de "Desenvolvimento da Pecuária Leiteira da Região de Viçosa - PDPL-RV" iniciou as atividades em outubro de 1988 e, atualmente, conta com mais um programa, que é o Programa de "Capacitação de Especialistas em Pecuária Leiteira - PCEPL", que atuam com os seguintes parceiros: Nestlé, Itambé, SEBRAE, Fundação de Amparo à Universidade Federal de Viçosa (FUNARBE), a própria Universidade Federal de Viçosa (UFV) e Dairy Partners Americas (DPA).
O PDPL-RV e o PCEPL têm caracteres educativo e sociocultural, devido aos objetivos principais, que são oferecer estágio aos acadêmicos dos cursos de Agronomia, Medicina Veterinária e Zootecnia da UFV, sendo estes os responsáveis por prestar a assistência técnica aos produtores de leite da região. Essa assistência técnica é uma iniciativa de utilidade pública, já que o serviço prestado é gratuito e leva aos possíveis beneficiários do Programa tecnologias que sejam competitivas e que levem ao aumento da produção econômica do leite, além do acompanhamento econômico-financeiro da propriedade que é feito, entre outros (PDPL-RV e PCEPL, 2013).

Pode-se observar que o Estado de Minas Gerais possui programas específicos para a Cadeia Produtiva do Leite que já são consolidados, mas que não possuem ações concretas e específicas para o tratamento dos dejetos e para a produção de biogás.

\section{Considerações finais}

Frente ao potencial existente no Estado de Minas Gerais para a implantação de uma pecuária leiteira mais eficiente e sustentável, faz-se necessário o ajuste das políticas de incentivo à adoção de técnicas e equipamentos que favoreçam uma melhor destinação dos dejetos e efluentes advindos da atividade leiteira, principalmente voltados aos pequenos e médios produtores rurais, que são maioria no Estado.

Percebeu-se que a cadeia produtiva do leite em Minas Gerais é consolidada e amparada por um Estado que investe na qualidade da produção de leite, com programas que têm como objetivo principal levar aos pequenos, médios e grandes produtores do Estado uma assistência técnica qualificada. Contudo, não há ações e incentivos bem definidos e divulgados que minimizem a problemática dos dejetos da bovinocultura de leite.

$\mathrm{O}$ atual programa mais adequado à produção de biogás no Brasil é o Programa $\mathrm{ABC}$, que possui maior preocupação com os impactos ambientais gerados pela produção animal, principalmente a poluição das águas, disponibilizando aos produtores uma linha de crédito específica para o tratamento dos dejetos.

Sendo assim, a contribuição deste trabalho teve a intenção de mostrar que existem várias leis e progra- 
mas de incentivo que estão relacionados às questões ambientais em geral, mas que, especificamente para a regulamentação da produção de biogás, as políticas públicas existentes ainda estão muito longe de serem ideais. Por isso, é de extrema importância e urgência que sejam feitos mais discussões e estudos que possam contribuir para a concretização da viabilidade econômica e financeira da produção de biogás no país, uma vez que essa pode vir a ser uma solução adequada dos pontos de vista econômico, financeiro, ambiental e social para a problemática dos resíduos da produção animal.

\section{Referências}

ALMG - Assembleia Legislativa de Minas Gerais. Constituição do Estado de Minas Gerais. Disponível em: < http://www.almg. gov.br/consulte/legislacao/?aba=js_tabConstituicaoEstadual $>$. Acesso em: 27/10/2013.

.Lei . $^{\circ} 20.922$ de 16/10/2013. Dispõe sobre a Política Florestal e de Proteção à Biodiversidade no Estado. Disponível em: <http://www.almg.gov.br/consulte/legislacao/completa/ completa-novamin.html?tipo $=$ LEI\&num $=20922 \&$ comp $=\&$ ano $=2013 \&$ texto $=$ original\#texto $>$. Acesso em: 27/10/2013.

Barbosa, G.; Langer, M. Uso de biodigestores em propriedades rurais: uma alternativa à sustentabilidade ambiental. UNOESC \& Ciência-ACSA, Joaçaba, 2(1), 87-96, jan./jun. 2011.

Beck. A. de M. O biogás de suínos como alternativa energética sustentável. In: Anais do XXVII Encontro Nacional de Engenharia de Produção, Foz do Iguaçu, 09 a 11 de outubro de 2007.

BNDES - Banco Nacional de Desenvolvimento Econômico e Social. Programa para Redução da Emissão de Gases de Efeito Estufa na Agricultura - Programa ABC. 2013. Disponível em: <http://www.bndes.gov.br/SiteBNDES/bndes/bndes_pt/ Institucional/Apoio_Financeiro/Programas_e_Fundos/abc. html >. Acesso em: 26/10/2013.

BRASIL. Ministério do Meio Ambiente. Resolução n. ${ }^{\circ} 430$, de 13 de maio de 2011. Dispõe sobre as condições e padrões de lançamento de efluentes, complementa e altera a Resolução n. ${ }^{\circ} 357$, de 17 de março de 2005, do Conselho Nacional do Meio Ambiente - CONAMA. Disponível em: $<$ http://www. $\mathrm{mma}$.gov.br/port/conama/legiabre.cfm?codlegi $=646>$. Acesso em: 22/05/2013.
Além disso, é necessário que instituições públicas e privadas, universidades e centros de pesquisa viabilizem a pesquisa e o desenvolvimento que permitam a conexão entre a cadeia produtiva da pecuária leiteira $\mathrm{e}$ a do biogás e que estejam sempre abertos a desenvolverem ações participativas, tais como reuniões, debates e mesas-redondas para discutir o como fazer para que haja uma maior interseção entre essas duas cadeias e que, consequentemente, o resultado positivo seja a expansão da produção de biogás em Minas Gerais e no Brasil.
CONAMA - Conselho Nacional do Meio Ambiente. Resolução $n^{\circ} 357$, de 17 de março de 2005. Dispõe sobre a Legislação Ambiental brasileira. Disponível em: <http://www.mma.gov. br/port/conama/>. Acesso em: 28/10/2013.

ELETROBRAS - Centrais Elétricas Brasileiras. Plano Anual do PROINFA - PAP 2013. 2012. 66 p. Disponível em: <http:// www.aneel.gov.br/cedoc/areh20121385_2.pdf $>$. Acesso em: $28 / 01 / 2014$

EMBRAPA Pecuária Sudeste - Empresa Brasileira de Pesquisa Agropecuária. Programa Balde Cheio. Disponível em: $<$ https://www.embrapa.br/pecuaria-sudeste $>$. Acesso em: 27/10/2013.

FAEMG - Federação da Agricultura e Pecuária do Estado de Minas Gerais. Programa Balde Cheio de Minas Gerais. Disponível em: $<$ http://www.faemg.org.br/Content.aspx?Co $\mathrm{de}=152 \&$ ParentCode $=151 \&$ ParentPath $=$ None $\&$ ContentVersi on $=\mathrm{R}>$. Acesso em: 27/10/2013.

FRAGMAQ. Biogás no Brasil: sua importância na matriz energética brasileira 2013. 2012.

Gaspar, R. M. B. L. Utilização de biodigestores em pequenas e médias propriedades rurais, com ênfase na agregação de valor: um estudo de caso na região de Toledo-PR. 106 f. Florianópolis, Dissertação (Mestrado em Engenharia de Produção) - Pós-Graduação em Engenharia de Produção, Universidade Federal de Santa Catarina, 2003.

ICLEI. Governos Locais pela Sustentabilidade. Secretariado para América Latina e Caribe. Manual para aproveitamento do 
biogás: volume um, aterros sanitários. 2009. 80 p. Escritório de projetos no Brasil, São Paulo.

Kunz, A.; Oliveira, P. A. V. O uso de biodigestores para tratamento de residuos animais. Embrapa, 2008. (folheto)

MAPA - Ministério da Agricultura, Pecuária e Abastecimento; MDA, Ministério do Desenvolvimento Agrário. Portaria Interministerial $n^{\circ}$ 984/2013. Dispõe sobre o Plano Setorial de Mitigação e de adaptação às mudanças climáticas para a consolidação de uma Economia de Baixa Emissão de Carbono na Agricultura - Plano ABC. Disponível em: <http://www. agricultura.gov.br/portal/page/portal/Internet-MAPA/pagina-inicial/desenvolvimento-sustentavel/plano-abc $>$. Acesso em: 27/10/2013.

. Plano Nacional da Agroenergia 2006-2011. 2. ed. rev. -Brasília, DF: Embrapa Informações Tecnológica, 2006. 110 p.

. Programa ABC. Disponível em: <http://www.agricultura.gov.br/desenvolvimento-sustentavel/plano-abc/>. Acesso em: 02/04/ 2013.

Machado, C. R. Biodigestão anaeróbia de dejetos de bovinos leiteiros submetidos a diferentes tempos de exposição ao ar. 53 p. Botucatu, Dissertação (Mestrado em Agronomia - Energia na Agricultura) - Faculdade de Ciências Agronômicas da Unesp, 2011.

MDA - Ministério do Desenvolvimento Agrário. Programas: Crédito Rural. Disponível em: $<$ http://portal.mda.gov.br/portal/ saf/programas/pronaf/2258856>. Acesso em: 22/05/2013.

MMA - Ministério do Meio Ambiente. Lei $n^{\circ} 12.651$, de 25 de maio de 2012. Dispõe sobre a proteção da vegetação nativa. Disponível em: <http://www.brasil.gov.br/meio-ambiente/2012/11/codigo-florestal $>$. Acesso em: 26/10/2013.

. Lei $n^{\circ} 18.031$, de 12 de janeiro de 2009. O Governo do Estado de Minas Gerais dispõe sobre a Política Estadual de Resíduos Sólidos. Disponível em: <http://www.siam.mg.gov. br/sla/download.pdf?idNorma=9272>. Acesso em: 26/10/2013.

MME - Ministério de Minas e Energia. PROINFA. Disponível em: <http://www.mme.gov.br/programas/proinfa $>$. Acesso em: 22/05/2013.

Oliveira, A. J. de; Ramalho, J. Plano Nacional de Agroenergia 2006 - 2011. Ministério da Agricultura, Pecuária e Abastecimento. Brasília, 2006. p. 110.

Oliveira, A. P. Potencial de produção e utilização de biogás na avicultura comercial. In: Encontro de avicultores do Estado de São Paulo. Jornada Técnica. Anais do Sindicato Rural de Bastos, Bastos, 2001. P. 16-28.

Oliveira, L. A.; Marques, F. S.; Hoepers, A. Dimensionamento do potencial de geração distribuida pela biomassa animal residual na bacia do Paraná 3. Foz do Iguaçu: ADEOP Agência de Desenvolvimento Regional do Extremo Oeste do Paraná, 2010.

Oliveira, P. A. V. de (Coord.). Manual de manejo e utilização dos dejetos de suínos. Concórdia: Embrapa CNPSA, 1993. $188 \mathrm{p}$.

Produção e aproveitamento do biogás. In:

(Coord.). Tecnologias para o manejo de resíduos na produção de suínos: manual de boas práticas. Concórdia: Embrapa Suínos e Aves, 2004. 109 p.

PDPL - RV e PCEPL - Programa de Desenvolvimento da Pecuária Leiteira da Região de Viçosa - MG. $P D P L-R V$. Disponível em: $<$ http://www.pdpl.ufv.br/pdpl/scripts/index. php>. Acesso em: 29/10/2013.

Salomon, R. K.; Tiago Filho, G. L. Biomassa (série Energias Renováveis). Itajubá. MG: FAPEPE, 2007. 36p.

SEAPA-MG - Secretaria de Agricultura, Pecuária e Abastecimento de Minas Gerais. Legislação Ambiental de Minas Gerais. Disponível em: <http://www.siam.mg.gov.br/sla/action/ Consulta.do $>$. Acesso em: 27/10/2013.

. Programa Minas Leite. Disponível em: <http://www. $\overline{\text { agricultura.mg.gov.br/programas-e-acoes/minas-leite }>\text {. Acesso }}$ em: 28/10/2013.

Centro de Análise e Estudos Estratégicos: dados do agronegócio. Disponível em: $<$ http://www.agricultura.mg.gov. br/dados-do-agronegocio $>$. Acesso em: 25/10/ 2013.

Sganzerla, E. Biodigestores: uma solução. Porto Alegre. Agropecuária, 1983.

Silva, C. L. da; Rabelo, J. M. de O.; Ramazzotte, V. das C. B.; Rossi, L. F. dos S.; Bollamann, H. A. A cadeia de biogás e a sustentabilidade local: uma análise socioeconômica ambiental da energia de resíduos sólidos urbanos do aterro da Caximba em Curitiba. Revista Innovar, 19(34), 83-98, 2009.

Souza, S. N. M. de; Pereira, W. C.; Nogueira, C. E. C.; Pavan, A. A.; Sordi, A. Custo da eletricidade gerada em conjunto motor gerador utilizando biogás da suinocultura. Acta Scientiarum. Technology, Maringá, 26(2), 127-133, 2004. 